Scientific Review Engineering and Environmental Sciences (2022), 31 (1), 47-62

Sci. Rev. Eng. Env. Sci. (2022), 31 (1)

https://srees.sggw.edu.pl

\title{
DETERMINING THE INFLUENCE OF POPULATION DENSITY ON THE LAND SURFACE TEMPERATURE BASED ON REMOTE SENSING DATA AND GIS TECHNIQUES: APPLICATION TO PRIZREN, KOSOVO
}

Key words: population density, LST, SUHI, GIS, remote sensing, Prizren

\section{Introduction}

Population (demographic pressure), in the process of urbanization, influences different types of natural land cover to be destroyed and changed/replaced with impervious materials very common in urban areas, such as concrete, asphalt, stone, metal, glass, and other materials which have low albedo values and which absorb heat, causing the released energy to increase (Buyantuyev \& Wu, 2009; Harlan \& Ruddell, 2011; Santamouris, Synnefa \& Karlessi, 2011). All of these developments cannot escape at all without radical changes. Such changes affect the reduction of the amount of oxygen produced by the natural soil cover; reduction in evaporation; increase of surface flow (urban runoff); absorption, storage, and increase of heat; deterioration of air quality; deterioration of water quality, etc. (Berila \& Dushi, 2021).

The process of urbanization has undergone a great and rapid development due to the high growth of the population. Such processes, which directly affect people, are of great importance. Therefore, such and similar processes lead to only one possitive path: positive development (Morefield, Fann, Grambsch, Raich \& Weaver, 2018; Berila \& Isufi, 2021a). Developments which in themselves have rapid rates and large changes, the effects, of course, will not be satisfactory. Such processes, during development, produce effects that are harmful. These effects consist of: increase of surfaces with impervious materials; reduction/destruction/damage of green areas; reduction/destruction/damage of natural surfaces; empowerment of materials 
with low albedo values - increase of temperature, etc. All these effects that we mention, to a large extent, are encountered in cities.

Based on the information discussed in the paragraphs above it is more than understandable and logical that if we were to make a comparison between cities and rural areas in terms of heat, we would clearly see that the temperatures will be higher in the former. It is precisely such effects and processes that have led to the emergence in these areas of a very harmful phenomenon with a host of negative effects - urban heat island (UHI) a phenomenon in which higher temperatures are encountered in urban areas compared to peripheral or rural areas (Wang, Zhang, Tsou $\& \mathrm{Li}, 2017)$. It is very important to note that the UHI phenomenon can appear in all areas in which natural surface changes are made with artificial ones and in those cases when the earth is left completely bare, regardless of whether it is in urban, peripheral, or rural area (Ursu, 2019). The increase of human activities in the cities will make the UHI phenomenon even stronger. This phenomenon, with all its negative effects, will seriously endanger the human population (especially those living in cities) (Mohajerani, Bakaric \& Jeffrey-Bailey, 2017; Peres, Lucena, Rotunno Filho \& de Almeida França, 2018). It is crucial that the municipalities, or other governmental authorities, emphasize the dangerousness of the UHI phenomenon, while proposing solutions (as much as possible).

The UHI phenomenon has three types - depending on how the temperature is measured (Fabrizi, Bonafoni \& Biondi, 2010; Sherafati, Saradjian \& Rabbani, 2018; Berila \& Isufi, 2021b; Isufi, Berila \& Bulliqi, 2021):

a) Canopy layer heat island (CLHI) - this layer lies approximately at the average height of buildings and is determined by measuring the air temperature at a height of $2 \mathrm{~m}$ above the ground. The CLHI has usually been measured using sensors mounted on fixed meteorological stations (Nichol, Fung, Lam \& Wong, 2009; Clay et al., 2016; Berila \& Isufi, 2021b; Isufi et al., 2021).

b) Boundary layer heat island (BLHI) - lies above the CLHI layer and can reach a thickness of up to $1 \mathrm{~km}$. It is measured using special platforms, such as radiosondes and aircraft (Berila \& Isufi, 2021b; Isufi et al., 2021).

c) Surface urban heat island (SUHI) - difference in radiant temperature between urban and non-urban surfaces. The measurement/determination of this layer is done using thermal remote sensors (Berila \& Isufi, 2021b; Isufi et al., 2021).

Science has made significant progress in how the UHI phenomenon can be measured. In regard to the method used by researchers, which entirely depends on the data the researchers has, the tools they retains, and the accuracy required. In cases when in the study area there are different restrictions on measuring the UHI phenomenon, such as the lack of equipment/instruments for measuring temperature and their inhomogeneous distribution (as in our case of the study area), then it is necessary to use GIS and remote sensing techniques (Berila \& Dushi, 2021). Using them to measure the UHI phenomenon represents SUHI, which is determined using geospatial technology through the calculation of the land surface temperature (Voogt \& Oke, 2003; Despini et al., 2016; Pour \& Voženílek, 2020).

During the hot season(s) and the day, SUHI values get higher and vice versa (Roth, Oke \& Emery, 1989; Yuan \& Bauer, 2007). The UHI phenomena have a lot of seasonal variation and the temperature values meas- 
ured with remote sensing techniques will also depend on the materials from which the buildings are built, the orientation and density of the buildings, etc. Consequently, a UHI can also appear in a sparsely populated area due to building construction materials and related activities.

The Republic of Kosovo has not yet been able to escape/avoid such changes and all the negative effects they bring. Due to the high density/activities of the population, the caused changes, and the surfaces with impervious materials, in the second largest city of Kosovo-Prizren, have caused quite noticeable challenges to appear, which require very careful and quick solutions.

The main goal of our work is to make a connection between the atmosphere and the land surface temperature in order to reach the identification of all areas that are affected and face the SUHI phenomenon; to map the summer SUHI for the entire Municipality of Prizren in order to see whether the cadastral zones with the highest population density (greater emphasis of human activities) are the ones that face the most with this phenomenon. Our other goal is to help the city leaders identify the areas that are attacked and endangered by the SUHI phenomenon so that they can take immediate action to mitigate this phenomenon in order that the population of those areas can live as healthy as possible.

\section{Study area}

Prizren is the second largest city in the Republic of Kosovo after Prishtina. The coordinates of Prizren are $42^{\circ} 00^{\prime}$ and $42^{\circ} 20^{\prime} \mathrm{N}$ and $20^{\circ} 30^{\prime}$ and $21^{\circ} 00^{\prime} \mathrm{E}$ (Fig. 1). It is a town

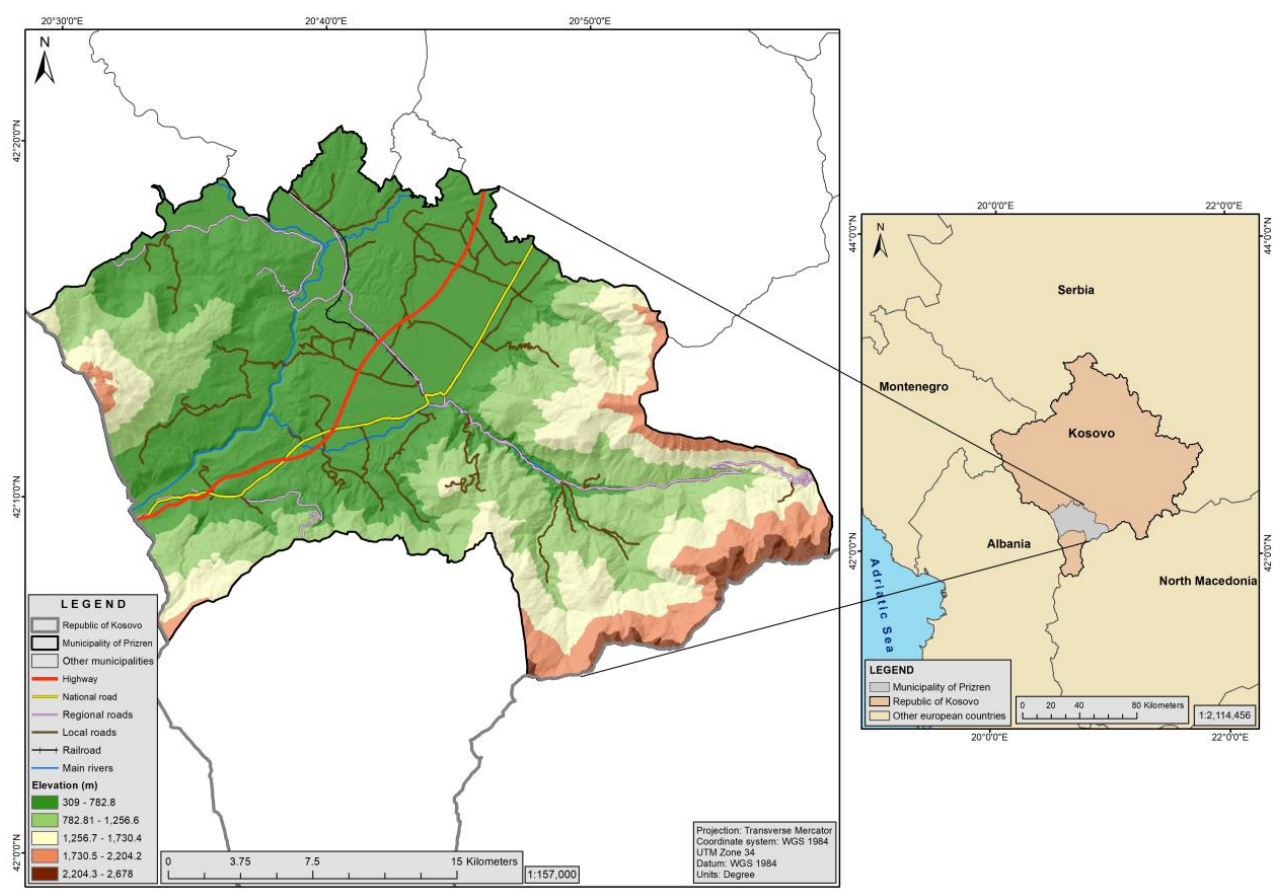

FIGURE 1. Location of the study area 
located on the slope of Sharri Mountain and along the Lumbardhi (Bistrica) river. The climate of Prizren has continental characteristics with a slight influence of the Mediterranean climate at lower altitudes, while in the mountains the harsh alpine climate dominates (UN-HABITAT, 2012). These climatic characteristics and mountain terrain are the reasons for the rich natural resources that contribute to the economic development of the country and the region (Universiteti Teknik i Stambollit, Urban Design Studio, Plan\&Art [UTS, UDS \& Plan\&Art], 2012).

We have compiled Figures 2 and 3 to have a clearer picture of the distribution of settlements in the city of Prizren, as well as to highlight and distinguish areas urbanized from areas with vegetation. Figure 2 presents CORINE land cover (CLC) of our study area of 2018 downloaded at the European Environment Agency (EEA). The main extension and predominance belong to the forest vegetation - at the edges of the southern, eastern, and western part. In the central and northern part, the area is occupied by activities of the population. Settlements are distributed in the Prizren area quite densely compared to the mountainous parts where we see a lower density of settlements. An uncontrolled and unplanned expansion is observed especially towards the main arterial roads. In particular the increase along the northwestern part poses a risk to agricultural land where there is irrigation infrastructure, which means bypassing the great potential for agricultural production. Misuse of agricultural land for construction has caused the degradation of natural resources and unsustainable develop-

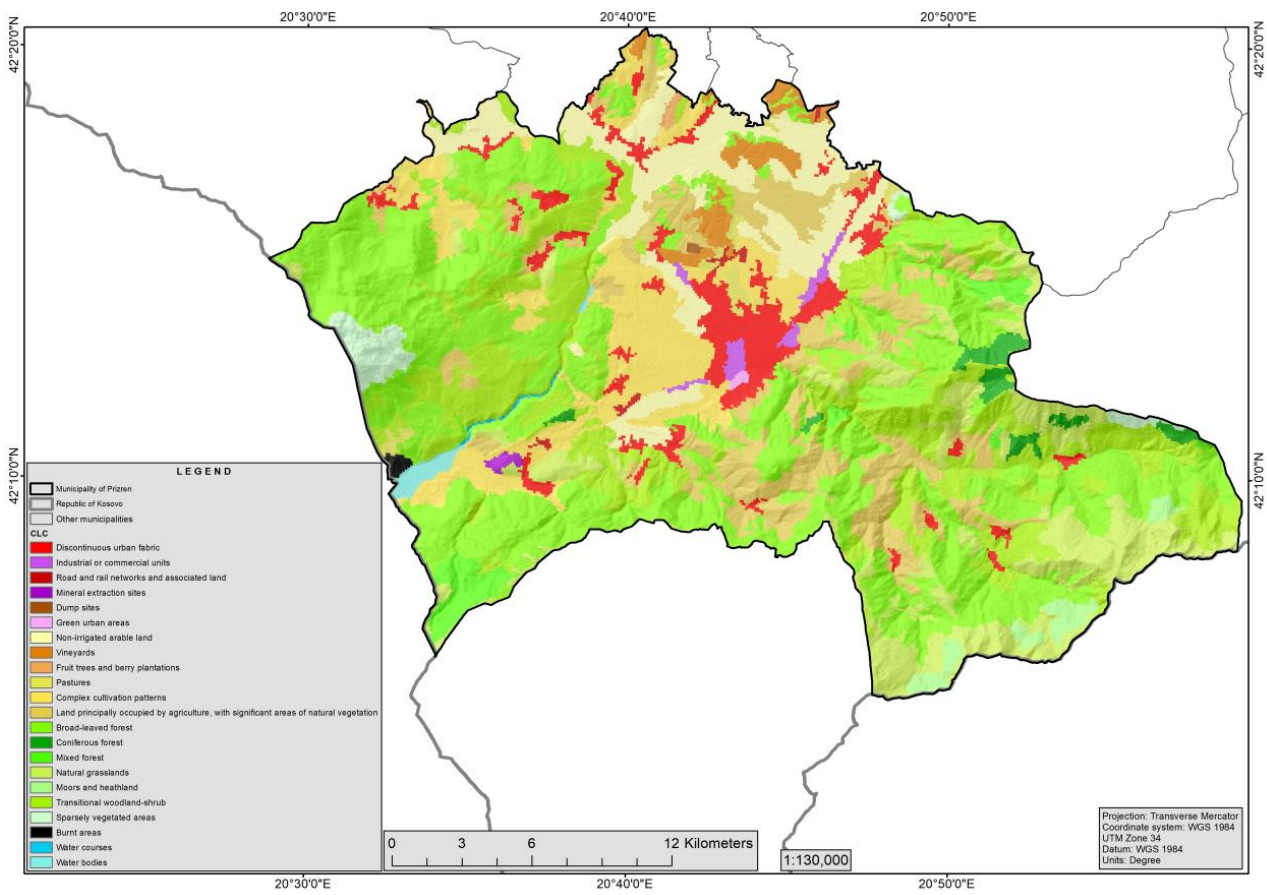

FIGURE 2. CORINE land cover of the study area 
Dushi, M., Berila, A. (2022). Determining the influence of population density on the land surface temperature based on remote sensing data and GIS techniques: application to Prizren, Kosovo. Sci. Rev. Eng. Env. Sci., 31 (1), 47-62. DOI 10.22630/srees.2324

ment. A large part of the agricultural land has been lost because of illegal gravel and quarry mining activities. The land is constantly being occupied with stone mining facilities which in turn causes the formation of informal settlements on the surrounding agricultural lands (UTS, UDS \& Plan\&Art, 2012).

Figure 3 presents a false-color composition of the optical satellite image of Landsat 8 - composition 764 (R: SWIR 2, G: SWIR 1, B: Red). Based on presented data, it is noticed that the built-up area lies mainly in the north, in the west, and in the central parts. Such an extension has been determined by the topography of this area. Most of the settlements are concentrated in the city center. The expansion of settlements continues along the north and the main road arteries that run through Prizren.

\section{Data and methods}

There are various methods for determining the surface heat of a given area. In our study, we determined the surface heat of the city of Prizren by calculating LST through GIS and remote sensing using satellite image of Landsat 8 . This paper used the satellite image of Landsat 8 on 8 August 2021. This satellite image had a negligible percentage of cloud cover $(0.01 \%)$ and we used the United States Geological Survey (USGS) website (https://earthexplorer.usgs.gov) to download it (Table 1). Our satellite image has been downloaded from Collection 1 and at a Level 1.

For the compilation of all maps in this study we used the program ArcGIS 10.5. In Figure 4 we have made a schematic presentation of the whole methodology that we

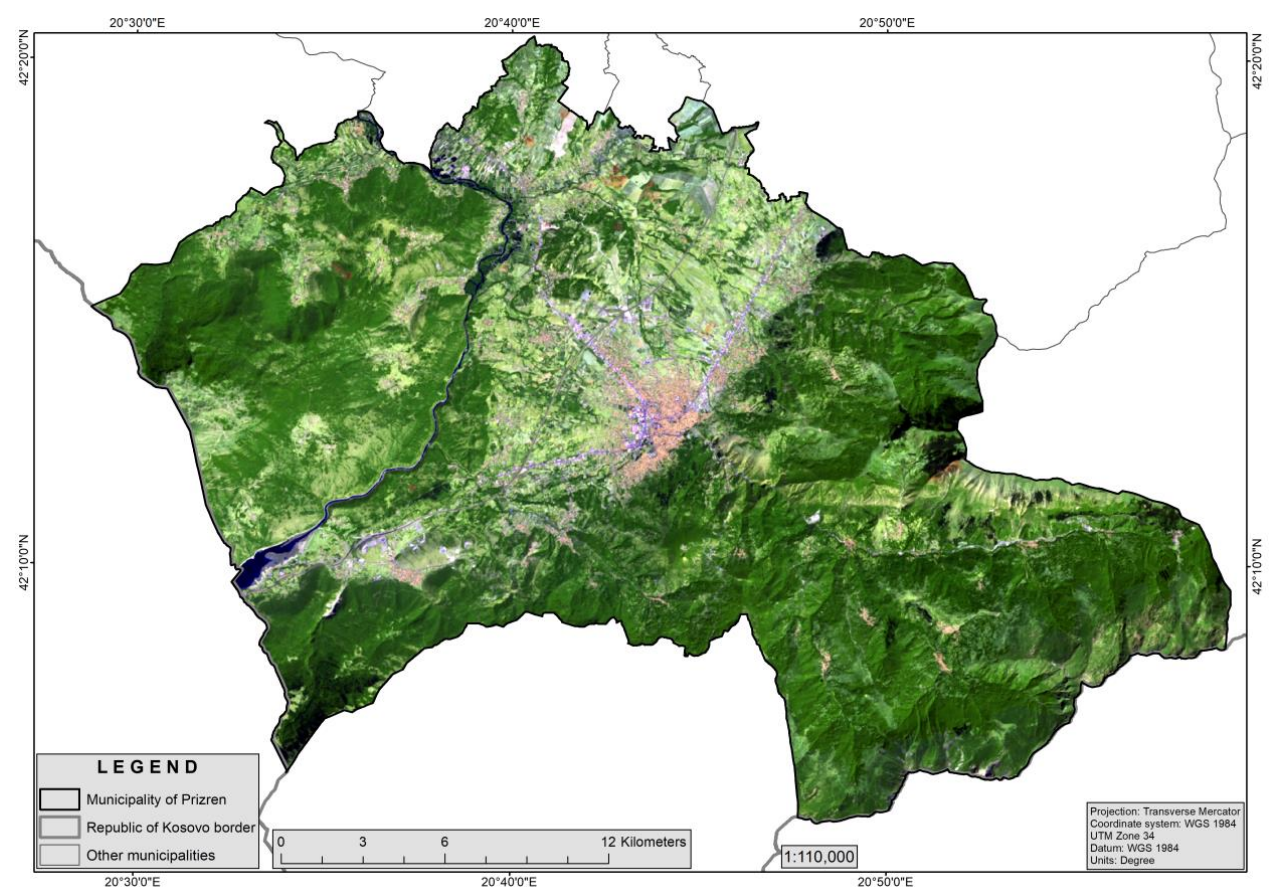

FIGURE 3. A false-color composition of optical satellite image of our study area (R: SWIR 2, G: SWIR 1, B: Red) 
Dushi, M., Berila, A. (2022). Determining the influence of population density on the land surface temperature based on remote sensing data and GIS techniques: application to

TABLE 1. Characteristics of the satellite image used in this study

\begin{tabular}{|l|c|c|c|c|c|c|}
\hline Sensor type & Date & Path/Row & $\begin{array}{c}\text { Cloud } \\
\text { cover }\end{array}$ & $\begin{array}{c}\text { Spatial } \\
\text { resolution }\end{array}$ & Format & Source \\
\hline Landsat 8 OLI/TIRS & 08.08 .2021 & $185 / 31$ & $0.01 \%$ & $30 \mathrm{~m}$ & tiff & https://earthexplorer.usgs.gov \\
\hline
\end{tabular}

have used in this paper. In this figure, we have presented in a general way all the steps we have taken to come to the mapping of the SUHI phenomenon and to determine the impact of population density on it. Whereas in the following sections, this article presents a detailed calculation for each part, in order to have better understanding of the methodology being used.
In Landsat 8 sensor satellite images, thermal data is stored in the form of digital numbers (DN) (Berila \& Isufi, 2021a). These numbers represent cells (pixels) that have not yet been calibrated into units (Käfer et al., 2020) that make sense (meaningful units). An important step to be taken is the return to radiance of DNs (Isaya Ndossi \& Avdan, 2016).

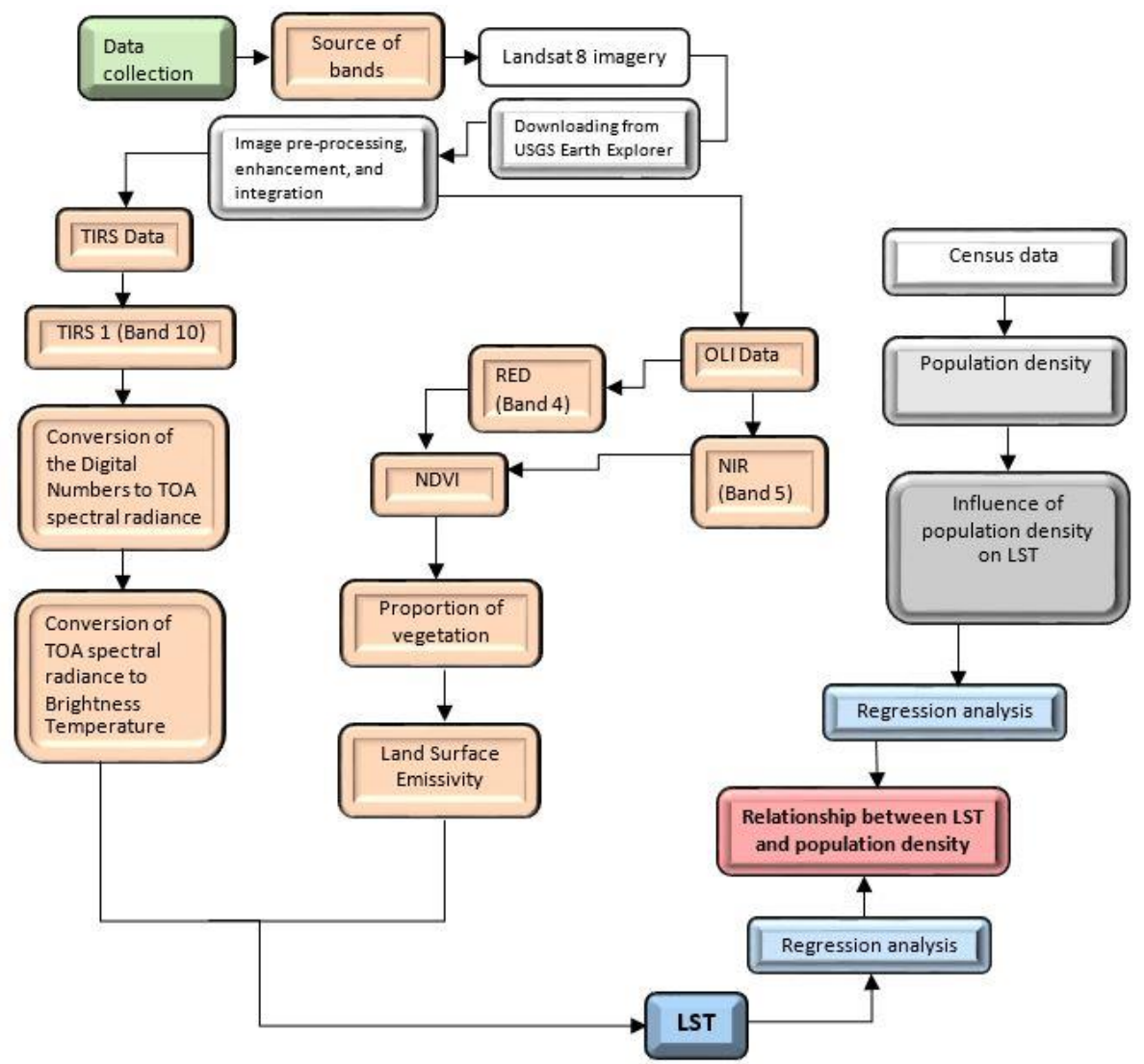

FIGURE 4. Flowchart depicting methodology 
The following equation was used to convert DNs of Band 10 (TIRS 1) to spectral radiance (United States Geological Survey [USGS], 2019) in the Landsat 8 TIRS sensor (Isaya Ndossi \& Avdan, 2016; Salih, Jasim, Hassoon \& Abdalkadhum, 2018; Berila \& Isufi, 2021a; Berila \& Dushi, 2021; Isufi et al., 2021):

$L_{\lambda}=M_{L} \cdot Q_{\text {cal }}+A_{L}$

where:

$L_{\lambda}$ - TOA spectral radiance $\left[\mathrm{W} \cdot \mathrm{m}^{-2} \cdot \mathrm{sr}^{-1}\right.$. $\left.\cdot \mu \mathrm{m}^{-1}\right]$,

$M_{L}$ - band-specific multiplicative rescaling factor from the metadata,

$Q_{c a l}$-quantized and calibrated standard product pixel values (DN),

$A_{L} \quad$ - band-specific additive rescaling factor from the metadata (Salih et al., 2018; Berila \& Isufi, 2021a; Isufi et al., 2021; Berila \& Dushi, 2021). The metadata of the satellite image is presented in Table 2.

Then, in the Landsat 8 satellite image MTL file, the reflectance rescaling coefficients were obtained. This was done to transform the OLI band into TOA planetary reflection (Adeyeri, Akinsanola \& Ishola, 2017). As per the above-mentioned calculation, the following equation was used (Adeyeri et al., 2017):

$$
\rho \lambda^{\prime}=M_{\rho} Q_{c a l}+A_{\rho}
$$

where:

$\rho \lambda^{\prime}$ - TOA planetary reflectance,

$M_{\rho}$ - band-specific multiplicative rescaling factor,

$A_{\rho}$ - band-specific additive rescaling factor.

Making the correction of TOA reflection with the angle of the sun, then is (USGS, 2019):

$$
\rho \lambda=\frac{\rho \lambda^{\prime}}{\cos \left(\theta_{s z}\right)}=\frac{\rho \lambda^{\prime}}{\sin \left(\theta_{s e}\right)}
$$

where:

$\rho \lambda^{\prime}$ - TOA planetary reflectance,

$\theta_{s z}$ - local solar zenith angle, $\theta_{s z}=90^{\circ}-\theta_{s e}\left[^{\circ}\right]$,

$\theta_{s e}$-local elevation angle of the sun $\left[^{\circ}\right]$ (USGS, 2019).

The dark object subtraction (DOS) method was used to remove small reflection values (due to air diffusion) (Chavez, 1996; Adeyeri et al., 2017). We used this method using ENVI 5.3 software as we did not have any other alternative for atmospheric measurements at our disposal (Adeyeri et al., 2017). The equation of an image corrected with DOS is (Adeyeri et al., 2017):

$$
L_{1} P=L_{1} \min -L_{1}(D 01 \%)
$$

where:

$L_{1}$ min - radiance corresponding to the minimum DN from the sum of all the pixels from the image $\left[\mathrm{W} \cdot \mathrm{m}^{-2} \cdot \mathrm{sr}^{-1} \cdot \mu \mathrm{m}^{-1}\right]$,

TABLE 2. Metadata of the satellite image

\begin{tabular}{|l|c|c|c|}
\hline Band & Variable & Description & Value \\
\hline \multirow{4}{*}{10} & - & thermal band & 774.8853 \\
\cline { 2 - 4 } & $K_{1}$ & thermal constant & 1321.0789 \\
\cline { 2 - 4 } & $K_{2}$ & & $3.3420 \mathrm{E}-04$ \\
\cline { 2 - 4 } & $M_{L}$ & band-specific multiplicative rescaling factor & 0.10000 \\
\cline { 2 - 4 } & $A_{L}$ & band-specific additive rescaling factor & \\
\hline
\end{tabular}


$L_{1}(D O 1 \%)$ - radiance of the dark object (DO) assumed to have a reflectance of 0.01 $\left[\mathrm{W} \cdot \mathrm{m}^{-2} \cdot \mathrm{sr}^{-1} \cdot \mu \mathrm{m}^{-1}\right]$ (Adeyeri et al., 2017).

In our study we used TIRS Band 10 because of the better performance it has shown compared to Band 11 (Montanaro, Gerace, Lunsford \& Reuter, 2014; Adeyeri et al., 2017; Berila \& Dushi, 2021).

\section{Calculation of brightness temperature}

The next step is to use constant values given in the metadata to convert spectral radiation to brightness temperature $\left(T_{b}\right)$. In order to convert radiance to brightness temperature, Equation (5) has been used in the study (Isaya Ndossi \& Avdan, 2016; USGS, 2019; Yuvaraj, 2020; Berila \& Dushi, 2021; Isufi et al., 2021).

$T_{b}=\frac{K_{2}}{\ln \left[\frac{K_{1}}{L_{\lambda}}+1\right]}$

where:

$T_{b}$ - at-sensor brightness temperature [K],

$L_{\lambda}$ - spectral radiance of thermal Band 10 $\left[\mathrm{W} \cdot \mathrm{m}^{-2} \mathrm{sr}^{-1} \cdot \mu \mathrm{m}^{-1}\right]$,

$K_{1}$ - band-specific thermal conversion constant from the metadata $\left[\mathrm{W} \cdot \mathrm{m}^{-2} \mathrm{sr}^{-1}\right.$. $\left.\cdot \mu \mathrm{m}^{-1}\right]$,

$K_{2}$ - band-specific thermal conversion constant from the metadata $[\mathrm{K}]$.

From the metadata for the given scene, it is possible and should be derived the values of $K_{1}$ and $K_{2}$ (Isaya Ndossi \& Avdan, 2016; Yakar \& Bilgi, 2019).

\section{Estimation of land surface emissivity}

To calculate land surface temperature ( $L S T)$, one of several options that exist is to evaluate land surface emissivity ( $L S E$ ) through normalized difference vegetation index $(N D V I)$ method (Kamran, Pirnazar
\& Bansouleh, 2015; Jiménez-Muńoz, Sobrino, Gillespie, Sabol \& Gustafson, 2016). The $d \varepsilon$ is the effect of the geometrical distribution of natural surfaces and internal reflections (Igun \& Williams, 2018; Carrasco et al., 2020; Isufi et al., 2021; Berila \& Dushi, 2021).

To calculate the emissivity, we rely on the following equation:

$d \varepsilon=\left(1-\varepsilon_{s}\right)\left(1-F_{v}\right) F_{\varepsilon_{v}}$

where:

$\varepsilon_{v}-$ vegetation emissivity,

$\varepsilon_{s}-$ soil emissivity,

$F_{v}$ - fractional vegetation,

$F$ - shape factor whose mean is 0.55 (Sobrino, Jiménez-Muńoz \& Paolini, 2004; Igun \& Williams, 2018; Guha \& Govil, 2020; Berila \& Dushi, 2021; Isufi et al., 2021).

$\varepsilon=\varepsilon_{v} \cdot F_{v}+\varepsilon_{S}\left(1-F_{v}\right)+d \varepsilon$

where:

$\varepsilon-$ emissivity.

From Equations (6) and (7), $\varepsilon$ may be determined by the following equation (Yuvaraj, 2020; Berila \& Dushi, 2021; Isufi et al., 2021):

$\varepsilon=0.004 \cdot F_{v}+0.989$

The proportion of vegetation $\left(F_{v}\right)$ is calculated based on the following equation (Wang et al., 2015; Yuvaraj, 2020; Berila \& Dushi, 2021; Isufi et al., 2021):

$F_{v}=\left[\frac{N D V I-N D V I_{\min }}{N D V I_{\max }-N D V I_{\min }}\right]^{2}$

The following equation is used to calculate NDVI with the help of Landsat visible Band 4 (Red) and NIR (Band 5) images 
(Yuvaraj, 2020; Berila \& Dushi, 2021; Isufi et al., 2021):

$$
N D V I=\frac{N I R-\text { Red }}{N I R+\text { Red }}=\frac{\text { Band } 5-B \text { Band } 4}{\text { Band } 5+B a n d 4}
$$

where:

NIR - near-infrared pixel values, Red - red band pixel values (Alemu, 2019).

The value of NDVI ranges between -1.0 and 1.0 (Alemu, 2019; Yuvaraj, 2020). High NDVI values indicate healthy vegetation while low values indicate less or no vegetation (Berila \& Dushi, 2021; Isufi et al., 2021).

\section{Calculation of land surface temperature}

The final step of estimating LST is as follows (Weng, Lu \& Schubring, 2004; Alemu, 2019; Yuvaraj, 2020; Berila \& Dushi, 2021; Isufi et al., 2021):

$$
L S T=\frac{T_{b}}{\left\{1+\left[\lambda \frac{T_{b}}{\rho}\right] \ln \varepsilon\right\}}
$$

where:

$\lambda$ - wavelength of emitted radiance by Landsat $8(\lambda=10.8$ acc. to the NASA $)$ [ $\mu \mathrm{m}]$,

$T_{b}$ - brightness temperature from which the $L S T$ values $[\mathrm{K}]$,

$\varepsilon-$ land surface emissivity,

$\rho$ - given by the following equation (Yuvaraj, 2020; Berila \& Dushi, 2021; Isufi et al., 2021):

$$
\rho=\mathrm{h} \frac{c}{\sigma}=14,388 \mu \mathrm{m} \cdot \mathrm{K}^{-1}
$$

where:

h - Planck's constant $\left(\mathrm{h}=6.626 \cdot 10^{-34}\right)$ $\left[\mathrm{J} \cdot \mathrm{s}^{-1}\right]$,

$\sigma$ - Boltzmann constant $\left(\sigma=1.38 \cdot 10^{-23}\right)$ $\left[\mathrm{J} \cdot \mathrm{K}^{-1}\right]$, $c$ - velocity of light $\left(c=2.988 \cdot 10^{8}\right)\left[\mathrm{m} \cdot \mathrm{s}^{-1}\right]$ (Alemu, 2019; Yuvaraj, 2020; Berila \& Dushi, 2021; Isufi et al., 2021).

There are various factors that can affect the generation and strengthening of $L S T$. In this paper we have tried to make a connection between $L S T$ and population density. To achieve this, LST was first calculated - from satellite thermal data - while the population density data by cadastral zones of the $\mathrm{Mu}$ nicipality of Prizren were obtained from the 2011 Kosovo Census, classified into four classes - from the least dense to the densest. These data, to have a better presentation on the map, are represented by proportional circles in black (Fig. 5). We have mapped and located these black circles as population density based on the spatial distribution of settlements through a topographic map with a scale of 1:25 000. Through this topographic map, we identified all settlements in each cadastral area of the Municipality of Prizren. And the last step was to place these points in each center of these settlements. This was done to make the relationship between population density and the spatial distribution of $L S T$ pixel values as real and fair as possible. The next step was to connect these layers of spatial data. For this, we used GIS techniques using ArcGIS 10.5 software. Using this software, we superposed these two layers of spatial data - as seen in Figure 5. All this work has been done to study and highlight the effect and importance of population density - as one of the main factors - in increasing and strengthening the values of $L S T$.

\section{Results and discussion}

In this paper, the data of the 2011 Kosovo census were used and a map representing the population density and LST in the city of 


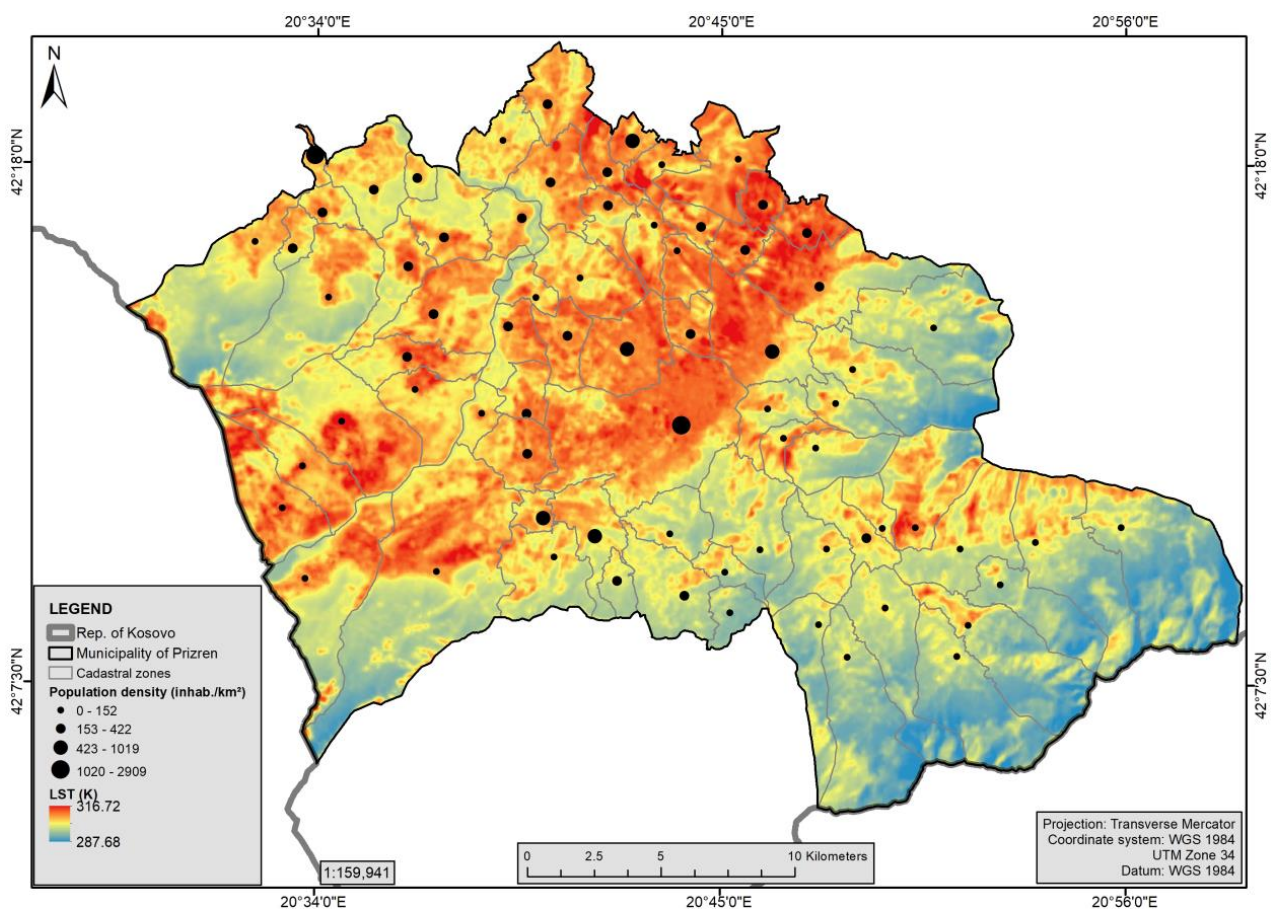

FIGURE 5. Spatial distribution of land surface temperature and population density of Prizren

Prizren was compiled. The population density was classified into four classes, starting from the least dense to the densest. Figure 5 clearly shows that the surfaces with the highest density are mainly the northern and central parts. Making the connection of population density with $L S T$ we can see that exactly in those areas where the highest population density is distinguished, are the areas (pixels) with the highest $L S T$ values. Here, the pixels with the lowest values are those with $287.68 \mathrm{~K}$, while the highest values of $L S T$ reach $316.72 \mathrm{~K}$. It is very important to understand the relationship that exists between $L S T$ and population density. Figure 5 shows that the lowest values of LST have natural surfaces - forests, water surfaces, parks, etc., while, on the other hand, higher values of $L S T$ can be distinguished in areas where the activities of the population are prominent and in spaces in which the surface of the earth is bare. Thus, if we compare natural surfaces with artificial ones, we notice that they have lower temperature values because they retain their freshness due to the reflection they make to the solar radiation.

The largest distribution of settlements is in the Prizren plain (center), while in the mountainous parts they begin to decrease. As the center of Prizren has experienced an uncontrolled expansion (especially towards the main arterial roads), the continuous expansion and extension of informal settlements pose a great risk in the loss of agricultural land and its transformation. A transformation of this natural surface is done with surfaces that are impervious, reducing the values of albedo and further strengthening the surface temperature (cause of heat absorption). 
To know the relationship between $L S T$ and population density, and to determine the impact of the latter on the former, Figure 6 presents the regression analysis between these two variables. From the results achieved, a strong positive connection can be noticed between the two. The logarithmic regression $(R)$ value is 0.8206 - showing a strong positive relationship. So, with the increase of population density, the values of $L S T$ are also increasing. This clearly indicates that an increase in population density will inevitably cause an increase in $L S T$ values. All this happens due to the increase of activities undertaken by the population in these areas.

In all areas with high density, the population takes a series of actions that change the natural surfaces due to the increase in demand. The most noticeable changes are the increase in the use of materials that have low albedo values. These actions are allowed to happen because there is no application of strict regulation in terms of planning in the city of Prizren. With this unplanned development trend, $L S T$ values will continue to rise to the extent that the health of the population will be extremely endangered.

The logarithmic regression equation between population density and $L S T$ is $y=2.3254 \ln (x)+295.59$. In addition, through this equation $L S T$ values can be predicted in case of increase of the (known) population density number for the future. It is population density that explains the variance of $L S T$ growth in urban areas. In $L S T$ values of cities, one of the main, important, and representative factors of such a rise is population growth. So, in other words, population density is being presented as the main factor and contributor to this urban change - in relation to the increase in $L S T$ values (Landsberg, 1981). Separating each factor that contributes to the increase in $L S T$ values in this major problem is not easy to do. However, one of those factors has shown and

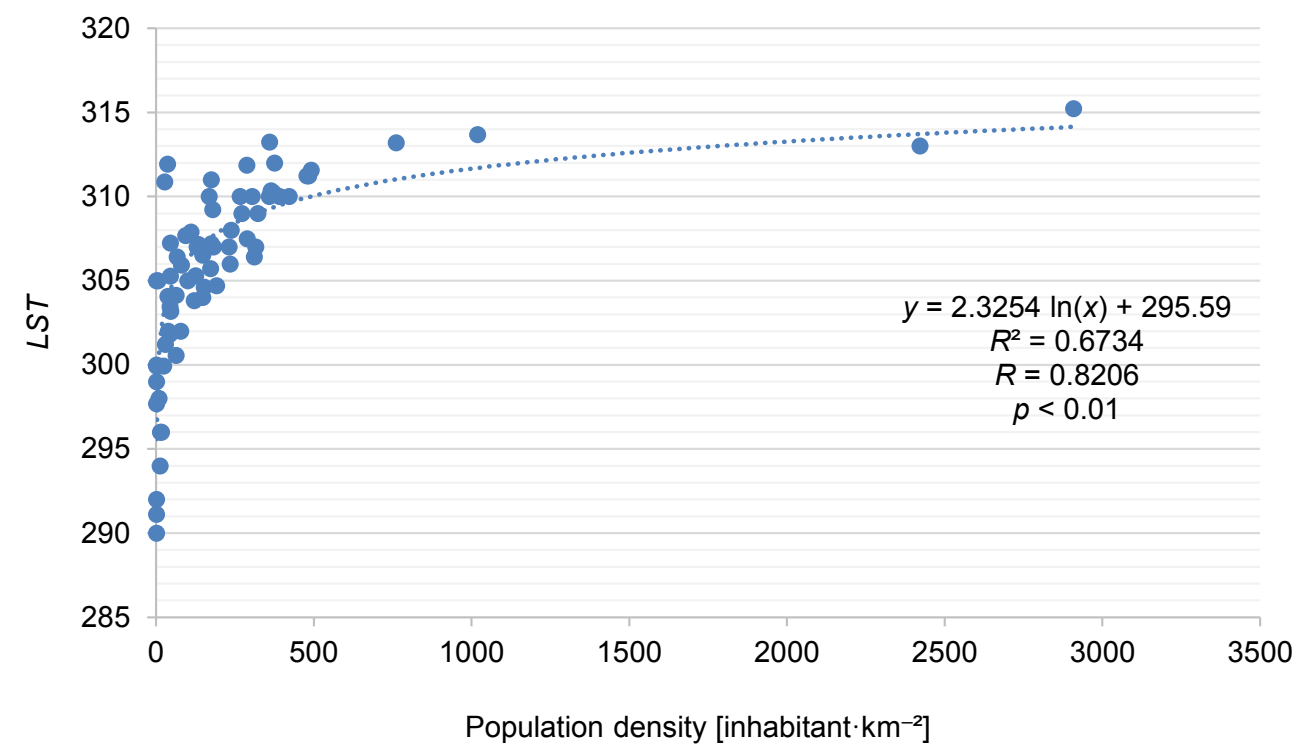

FIGURE 6. Scatter plot between land surface temperature and population density 
proved that it has a strong connection with LST or the UHI phenomenon is the population density (Lo \& Faber, 1998). The small number of meteorological stations in which the temperature of the earth's surface is measured - both in the past and today - is presented as a big obstacle because, in this way, there is no fair and accurate representation for all study area. Facing such situations, the solution is to measure the land's temperature using thermal satellite data. This study clearly presents the spatial change of LST in Prizren. One of the main factors that clearly contribute to the increase of $L S T$ values in our study area is the high population density. This study of ours highlights a close link that exists between $L S T$ and population density. Statistical analysis of logarithmic regression reveals that the population is a factor that contributes to the increase of $L S T$ values, thus making the UHI phenomenon to be generated and strengthened precisely in those parts - also creating the microclimate of Prizren.

Similar results as in our paper were seen in the work of Li et al. (2014) on the impact of land cover and population density on soil surface temperature - Wuhan (China). The results of this study showed that the regions with high LST were concentrated in residential and industrial areas with low vegetation coverage, in which the population with their activities had made continuous changes. Similar results have been reported by Mallick (2021). In his work on seasonal characteristics of surface temperature with $N D V I$ and population density in the National Capital Region (India), he finds that the high population density is one of the main contributing factors in generating and enhancing UHI intensity and in creating a microclimate.
Song et al. (2020) in the study on the effects of building density on soil surface temperature in China, found that in increasing $L S T$ values, in addition to the density of buildings, climate also plays an important role - the drier the climate, the greater the impact of the density of buildings on increasing LST values. Gang, QuiPing, RongBo and DongSheng (2019) in their work on the effects of land use, population density, and altitude on the UHI phenomenon found that $L S T$ is significantly related to population density, altitude, and proportions of different types of land use. According to them, the larger the artificial surface, the more powerful the UHI intensity and vice versa.

The biggest environmental challenge of the Municipality of Prizren is the irrational use of natural resources, which results in pollution and degradation of the environment, which is affecting the further strengthening of the SUHI phenomenon. The unplanned development of agricultural land resulting from the use of it for the construction of settlements along the main regional roads has resulted in a major loss - it should be borne in mind that any change and replacement of natural to artificial areas only contributes to the deterioration of the situation with SUHI.

\section{Conclusions}

This study of ours uses geospatial technology to present as clearly and correctly as possible the spatial distribution of $L S T$ and its relationship with the density of the population living in Prizren. The satellite image on 8 August 2021 was used to determine the impact of population density on the strengthening of the earth's surface temperature. To do this, LST was calculated and Landsat 8 
TIRS and OLI bands were used. For the entire Municipality of Prizren, $L S T$ showed that it has a great connection with vegetation, strengthening once again what is now known that the greener areas, the fresher it will be and vice versa. On the other hand, the cartographic representation of the spatial distribution of $L S T$ clearly showed that areas in which the population density is high increase the impact of the SUHI effect. All areas affected by the SUHI phenomenon were identified for the entire Municipality of Prizren. These areas are located mainly in the north, center, and west. It is in these areas that the density and activities of the population are most pronounced. Based on this, we conclude that areas in which the population density is high have a significant effect on the generation and strengthening of the phenomenon harmful to the population such as SUHI.

The importance of the maps in which the SUHI phenomenon is defined is also shown by our study. This is because it becomes possible to identify all areas in which this harmful phenomenon causes concern for residents living. Also, these types of maps help municipal administrators to act against this phenomenon in those areas where $L S T$ values are high, such as replacing black materials with materials with high albedos, expanding of green areas, the expansion of water areas for more freshness, the application of green roofs and a series of other actions which make the life of these citizens healthier.

We raise the concern for policymakers in the Municipality of Prizren to take all steps which minimize the SUHI effect as soon as possible. Studies like ours should raise the alarm in the whole human society for a better life. At the same time, we need strict control of all actions of the population because this trend of increasing population density, increasing demand for water, land, energy, etc., which is characterizing Prizren, will make its surroundings lose its existing green spaces. Based on this, the authors raise alarm and concern to government institutions to take all this information in this paper with the utmost seriousness and use it for all future activities which are planned to take place in Prizren.

\section{References}

Adeyeri, O. E., Akinsanola, A. A. \& Ishola, K. A. (2017). Investigating surface urban heat island characteristics over Abuja, Nigeria: Relationship between land surface temperature and multiple vegetation indices. Remote Sensing Applications: Society and Environment, 7, 57-68.

Alemu, M. M. (2019). Analysis of Spatio-Temporal Land Surface Temperature and Normalized Difference Vegetation Index Changes in the Andassa Watershed, Blue Nile Basin, Ethiopia. Journal of Resources and Ecology, 10 (1), 77-85.

Berila, A. \& Dushi, M. (2021). Measuring Surface Urban Heat Island in response to population density based on Remote Sensing data and GIS techniques: application to Prishtina, Kosovo. Folia Geographica, 63 (2), 38-57.

Berila, A. \& Isufi, F. (2021a). Two decades (2000-2020) measuring urban sprawl using GIS, RS and landscape metrics: a case study of Municipality of Prishtina (Kosovo). Journal of Ecological Engineering, 22 (6), 114-125.

Berila, A. \& Isufi, F. (2021b). Mapping summer SUHI and its impact on the environment using GIS and Remote Sensing techniques: a case study on Municipality of Prishtina (Kosovo). European Journal of Geography, $12(3), 113-129$.

Buyantuyev, A. \& Wu, J. (2009). Urban heat islands and landscape heterogeneity: linking spatiotemporal variations in surface temperatures to land-cover and socioeconomic patterns. Landscape Ecology, 25 (1), 17-33. 
Dushi, M., Berila, A. (2022). Determining the influence of population density on the land surface temperature based on remote sensing data and GIS techniques: application to

Carrasco, R. A., Pinheiro, M. M. F., Junior, J. M., Cicerelli, R. E., Silva, P. A., Osco, L. P. \& Ramos, A. P. M. (2020). Land use/land cover change dynamics and their effects on land surface temperature in the western region of the state of Săo Paulo, Brazil. Regional Environmental Change, 20 (3), 1-12.

Chavez, P. S. (1996). Image-based atmospheric corrections - revisited and improved. Photogrammetric Engineering and Remote Sensing, 62 (9), 1025-1036.

Clay, R., Guan, H., Wild, N., Bennett, J., Vinodkumar \& Ewenz, C. (2016). Urban Heat Island traverses in the City of Adelaide, South Australia. Urban Climate, 17, 89-101.

Despini, F., Ferrari, C., Bigi, A., Libbra, A., Teggi, S., Muscio, A. \& Ghermandi, G. (2016). Correlation between remote sensing data and ground based measurements for solar reflectance retrieving. Energy and Buildings, 114, 227-233.

Fabrizi, R., Bonafoni, S. \& Biondi, R. (2010). Satellite and ground-based sensors for the urban heat island analysis in the city of Rome. Remote Sensing, 2 (5), 1400-1415.

Gang, W., QiuPing, Z., RongBo, X. \& DongSheng, G. (2019). On impacts of land use, population density and altitude on the urban heat island. Journal of Yunnan University - Natural Sciences Edition, 41 (1), 82-90.

Guha, S. \& Govil, H. (2020). Land surface temperature and normalized difference vegetation index relationship: a seasonal study on a tropical city. SN Applied Sciences, 2 (10), $1-14$.

Harlan, S. L. \& Ruddell, D. M. (2011). Climate change and health in cities: impacts of heat and air pollution and potential co-benefits from mitigation and adaptation. Current Opinion in Environmental Sustainability, 3 (3), 126-134.

Igun, E. \& Williams, M. (2018). Impact of urban land cover change on land surface temperature. Global Journal of Environmental Science and Management, 4 (1), 47-58.

Isaya Ndossi, M. \& Avdan, U. (2016). Application of open source coding technologies in the production of Land Surface Temperature (LST) maps from Landsat: a PyQGIS plugin. Remote Sensing, 8(5), 413. https://doi. org/10.3390/rs8050413
Isufi, F., Berila, A. \& Bulliqi, S. (2021). Measuring UHI using Landsat 8 OLI and TIRS data with NDVI and NDBI in Municipality of Prishtina. Disaster Advances, 14 (11), 25-36.

Jiménez-Muńoz, J. C., Sobrino, J. A., Gillespie, A., Sabol, D. \& Gustafson, W. T. (2006). Improved land surface emissivities over agricultural areas using ASTER NDVI. Remote Sensing of Environment, 103 (4), 474-487.

Käfer, P. S., Rolim, S. B. A., Diaz, L. R., Rocha, N. S. da, Iglesias, M. L. \& Rex, F. E. (2020). Comparative analysis of split-window and single-channel algorithms for land surface temperature retrieval of a pseudo-invariant target. Boletim de Cięncias Geodésicas, $26(2), 1-17$.

Kamran, K. V., Pirnazar, M. \& Bansouleh, V. F. (2015). Land surface temperature retrieval from Landsat 8 TIRS: comparison between split window algorithm and SEBAL method. Third International Conference on Remote Sensing and Geoinformation of the Environment (RSCy2015), 9535, 11-22.

Landsberg, H. E. (1981). The urban climate. Cambridge, MA: Academic Press.

Li, L., Tan, Y., Ying, S., Yu, Z., Li, Z. \& Lan, H. (2014). Impact of land cover and population density on land surface temperature: case study in Wuhan, China. Journal of Applied Remote Sensing, 8(1), 084993. https://doi. org/10.1117/1.JRS.8.084993

Lo, C. \& Faber, J. B. (1998). Integration of landsat thematic mapper and census data for quality of life assessment. Remote Sensing of Environment, 62 (2), 143-157.

Mallick, J. (2021). Evaluation of Seasonal Characteristics of Land Surface Temperature with NDVI and Population Density. Polish Journal of Environmental Studies, 30 (4), 3163-3180.

Mohajerani, A., Bakaric, J. \& Jeffrey-Bailey, T. (2017). The urban heat island effect, its causes, and mitigation, with reference to the thermal properties of asphalt concrete. Journal of Environmental Management, 197, 522-538.

Montanaro, M., Gerace, A., Lunsford, A. \& Reuter, D. (2014). Stray light artifacts in imagery from the Landsat 8 thermal infrared sensor. Remote Sensing, 6 (11), 10435-10456. 
Dushi, M., Berila, A. (2022). Determining the influence of population density on the land surface temperature based on remote sensing data and GIS techniques: application to Prizren, Kosovo. Sci. Rev. Eng. Env. Sci., 31 (1), 47-62. DOI 10.22630/srees.2324

Morefield, P., Fann, N., Grambsch, A., Raich, W., \& Weaver, C. (2018). Heat-related health impacts under scenarios of climate and population change. International Journal of Environmental Research and Public Health, 15 (11), 2438. https://doi.org/10.3390/ijerph15112438

Nichol, J. E., Fung, W. Y., Lam, K. \& Wong, M. S. (2009). Urban heat island diagnosis using ASTER satellite images and "in situ" air temperature. Atmospheric Research, 94 (2), 276-284.

Peres, L. F., Lucena, A. J., Rotunno Filho, O. C. \& Almeida França, J. R. de (2018). The urban heat island in Rio de Janeiro, Brazil, in the last 30 years using remote sensing data. International Journal of Applied Earth Observation and Geoinformation, 64, 104-116.

Pour, T. \& Voženílek, V. (2020). Thermal data analysis for urban climate research: A case study of Olomouc, Czechia. Geographia Cassoviensis, 14 (1), 77-91.

Roth, M., Oke, T. R., \& Emery, W. J. (1989). Satellite-derived urban heat islands from three coastal cities and the utilization of such data in urban climatology. International Journal of Remote Sensing, 10 (11), 1699-1720.

Salih, M. M., Jasim, O.Z., Hassoon, K. I. \& Abdalkadhum, A. J. (2018). Land surface temperature retrieval from LANDSAT- 8 thermal infrared sensor data and validation with infrared thermometer camera. International Journal of Engineering \& Technology, 7 (4.20), 608-612.

Santamouris, M., Synnefa, A. \& Karlessi, T. (2011). Using advanced cool materials in the urban built environment to mitigate heat islands and improve thermal comfort conditions. Solar Energy, 85 (12), 3085-3102.

Sherafati, S., Saradjian, M. R. \& Rabbani, A. (2018). Assessment of surface urban heat island in three cities surrounded by different types of land-cover using satellite images. Journal of the Indian Society of Remote Sensing, 46 (7), 1013-1022.

Sobrino, J. A., Jiménez-Muńoz, J. C. \& Paolini, L. (2004). Land surface temperature retrieval from LANDSAT TM 5. Remote Sensing of Environment, 90 (4), 434-440.

Song, J., Chen, W., Zhang, J., Huang, K., Hou, B. \& Prishchepov, A. V. (2020). Effects of building density on land surface temperature in China: Spatial patterns and determinants. Landscape and Urban Planning, 198, 103794. https://doi.org/10.1016/j.landurbpla n.2020.103794

UN-HABITAT (2012). Prizren Municipal Development Plan 2025 Strategic Environmental Assessment (SEA) Report (draft). Kosovo. Retrieved from: http:/unhabitat-kosovo. org/old/repository/docs/SEA_Prizren_draft 786745.pdf

United States Geological Survey [USGS] (2019). Landsat 8 (L8). Data Users Handbook. LSDS-1574. Ver. 5.0. USGC EROS Center, Sioux Falls, SD. Retrieved from: https://prdwret.s3.us-west-2.amazonaws.com/assets/ palladium/production/atoms/files/LSDS1574 L8 Data Users Handbook-v5.0.pdf

Universiteti Teknik i Stambollit, Urban Design Studio, Plan\&Art [UTS, UDS \& Plan \&Art] (2012). Plani Zhvillimor i Komunës së Prizrenit 2013-2025. Retrieved from: https://www.online-transparency.org/repository/docs/Plani_Zhvillimor_i_Komunes se Prizrenit_2013-20251.pdf [access 15.02. 2021].

Ursu, C. D. (2019). The Land Surface Temperature evolution (LST) using landsat scenes. Case study: the industrial platform Săvineşti. Geographia Technica, 14 (2), 131-142.

Voogt, J. A. \& Oke, T. R. (2003). Thermal remote sensing of urban climates. Remote Sensing of Environment, 86 (3), 370-384.

Wang, F., Qin, Z., Song, C., Tu, L., Karnieli, A. \& Zhao, S. (2015). An improved mono-window algorithm for Land Surface Temperature retrieval from Landsat 8 thermal infrared sensor data. Remote Sensing, 7 (4), 4268-4289.

Wang, H., Zhang, Y., Tsou, J. \& Li, Y. (2017). Surface urban heat island analysis of Shanghai (China) based on the change of land use and land cover. Sustainability, 9 (9), 1538. https://doi.org/10.3390/su9091538

Weng, Q., Lu, D. \& Schubring, J. (2004). Estimation of land surface temperature-vegetation abundance relationship for urban heat island studies. Remote Sensing of Environment, 89 (4), 467-483.

Yakar, İ. \& Bilgi, S. (2019). Land Surface Temperature mapping by the use of Remote Sensing and GIS: case study of Istanbul 
metropolitan area. In H. M. Yilmaz et al. (eds.), X. Teknik Sempozyumu. Türkiye Ulusal Fotogrametri ve Uzaktan Algılama Birliği (pp. 77-81). Aksaray: Basım.

Yuan, F. \& Bauer, M. E. (2007). Comparison of impervious surface area and normalized difference vegetation index as indicators of surface urban heat island effects in Landsat imagery. Remote Sensing of Environment, 106 (3), 375-386.

Yuvaraj, R. M. (2020). Extents of Predictors for Land Surface Temperature Using Multiple Regression Model. The Scientific World Journal, 2020, 3958589. https://doi. org/10.1155/2020/3958589

\section{Summary}

Determining the influence of population density on the land surface temperature based on remote sensing data and GIS techniques: application to Prizren, Kosovo. The whole study was conducted for the Municipality of Prizren and aims to determine the effect that the population density has on land surface temperature (LST). All this was achieved through the connection of $L S T$ and population density. The free Landsat 8 satellite image downloaded from the United States Geological Survey website was used and then processed using GIS and remote sensing techniques. To understand this relationship, we performed a regression analysis. This analysis showed a strong positive relationship with a value of $r=0.8206$, emphasizing the important role that the population has in creating empowering areas that generate surface urban heat island (SUHI) effect. The results of the study clearly showed that in the northern, central, and western parts there are pixels with high $L S T$ values. This presentation corresponds with the population density, which means that it is precisely the actions of the population that help generate, display, and strengthen the harmful effect of the SUHI. The map in which the areas of high LST pixels are clearly identified is of great importance to the policymakers and urban planners of Prizren so that they can orient themselves in these areas and take all actions necessary to minimize this harmful effect which is worrying citizens. If it continues with unplanned development, the peripheral parts of Prizren are seriously endangered by the damage of the spaces which offer protection (green spaces) from the SUHI phenomenon, and the future generations will suffer even worse than the current ones from these irresponsible actions. 